\section{Basic and Applied Ecology}

www.elsevier.com/locate/baae

\title{
Parasitism-mediated prey selectivity in laboratory conditions and implications for biological control
}

\author{
Rafael de Andrade Moral ${ }^{\mathrm{a}, *}$, Clarice Garcia Borges Demétrio ${ }^{\mathrm{a}}$, John Hinde ${ }^{\mathrm{b}}$, \\ Wesley Augusto Conde Godoy ${ }^{\mathrm{c}}$, Francisco Sales Fernandes ${ }^{\mathrm{c}}$ \\ ${ }^{a}$ Departamento de Ciências Exatas, Escola Superior de Agricultura Luiz de Queiroz, Universidade de São Paulo \\ (USP), Av. Pádua Dias, 11, 13418-900 Piracicaba, SP, Brazil \\ ${ }^{\mathrm{b}}$ School of Mathematics, Statistics and Applied Mathematics, National University of Ireland, University Rd., \\ Galway, Ireland \\ ${ }^{\mathrm{c}}$ Departamento de Entomologia e Acarologia, Escola Superior de Agricultura Luiz de Queiroz, Universidade de São \\ Paulo (USP), Av. Pádua Dias, 11, 13418-900 Piracicaba, SP, Brazil
}

Received 4 April 2016; accepted 21 November 2016

Available online 6 December 2016

\begin{abstract}
In agroecosystems, parasitoids and predators may exert top-down regulation and predators for different reasons may avoid or give preference to parasitised prey, i.e., become an intraguild predator. The success of pest suppression with multiple natural enemies depends essentially on predator-prey dynamics and how this is affected by the interplay between predation and parasitism. We conducted a simple laboratory experiment to test whether predators distinguished parasitised prey from nonparasitised prey and to study how parasitism influenced predation. We used a host-parasitoid system, Spodoptera frugiperda and one of its generalist parasitoids, Campoletis flavicincta, and included two predators, the stinkbug Podisus nigrispinus and the earwig Euborellia annulipes. In the experiment, predators were offered a choice between non-parasitised and parasitised larvae. We observed how long it took for the predator to attack a larva, which prey was attacked first, and whether predators opted to consume the other prey after their initial attack. Our results suggest that, in general, female predators are less selective than males and predators are more likely to consume non-parasitised prey with this likelihood being directly proportional to the time taken until the first prey attack. We used statistical models to show that males opted to consume the other prey with a significantly higher probability if they attacked a parasitised larva first, while females did so with the same probability irrespective of which one they attacked first. These results highlight the importance of studies on predator-parasitoid interactions, as well as on coexistence mechanisms in agroecosystems. When parasitism mediates predator choice so that intraguild predation is avoided, natural enemy populations may be larger, thus increasing the probability of more successful biological control.
\end{abstract}

\section{Zusammenfassung}

In Agrarökosystemen können Parasitoide und Prädatoren 'top-down'-Kontrolle ausüben. Aus unterschiedlichen Gründen können Prädatoren parasitierte Beutetiere meiden oder präferieren. Der Erfolg der Schädlingskontrolle mit mehreren Antagonisten hängt entscheidend von der Räuber-Beute-Dynamik ab und davon, wie diese vom Wechselspiel zwischen Prädation und Parasitismus beeinflusst wird. Wir führten ein einfaches Laborexperiment durch, um zu prüfen, ob Räuber zwischen parasitierten und nicht parasitierten Beutetieren unterschieden und um zu untersuchen, wie Parasitierung die Prädation beeinflusste.

\footnotetext{
${ }^{*}$ Corresponding author.

E-mail address: rafael.moral@usp.br (R.d.A. Moral).
} 
Wir nutzten ein Wirt-Parasitoid-System mit Spodoptera frugiperda und einem seiner generalistischen Parasitoide, Campoletis flavicincta, und nahmen zwei Räuber hinzu: die Schildwanze Podisus nigrispinus und den Ohrwurm Euborellia annulipes. Den Räubern wurden eine nicht parasitierte und eine parasitierte Spodoptera-Raupe zur Auswahl angeboten. Wir beobachteten, wie lange ein Räuber benötigt, bis er eine Raupe attackiert, welcher Beutetyp zuerst angegriffen wurde und ob sich die Prädatoren nach einer ersten Attacke entschieden, den anderen Beutetyp zu fressen. Unsere Ergebnisse legen nahe, dass generell weibliche Räuber weniger selektiv sind als männliche und dass die Räuber mit höherer Wahrscheinlichkeit nicht parasitierte Beute fressen, wobei diese Wahrscheinlichkeit der Zeit bis zum ersten Angriff direkt proportional ist. Wir nutzten statistische Modelle, um zu zeigen, dass sich Männchen mit signifikant höherer Wahrscheinlichkeit entschieden, die andere Beute zu fressen, wenn sie als erste die parasitierte Raupe attackiert hatten, während Weibchen mit derselben Wahrscheinlichkeit fraßen, unabhängig davon, welchen Beutetyp sie zuerst attackiert hatten. Diese Ergebnisse stellen die Bedeutung von Untersuchungen zu RäuberParasitoid-Interaktionen unter Beweis, aber auch solche zu Koexistenzmechanismen in Agrarökosystemen. Wenn Parasitierung die Wahl des Räubers so beeinflusst, dass 'intraguild predation' vermieden wird, können die Populationen von natürlichen Gegenspielern größer sein, wodurch eine erfolgreichere biologische Kontrolle wahrscheinlicher wird.

() 2016 Gesellschaft für Ökologie. Published by Elsevier GmbH. All rights reserved.

Keywords: Indirect intraguild predation; Mover-stayer model; Multiple natural enemies; Parasitism-mediated predation; Pest suppression

\section{Introduction}

Biological control strategies may involve multiple natural enemies. In such cases, ecological interactions amongst control agents and the pest must be studied prior to release in the field, as effects on pest suppression may be non-additive (Ferguson \& Stiling 1996; Cardinale, Harvey, Gross, \& Ives 2003). The degree to which natural enemies affect food webs in agroecosystems varies and depends upon species' interactions and life-history trade-offs. In this sense, when two or more generalist predators are used to control the same pest, it is important to assess to what extent their niches overlap, and whether there is spatial and/or temporal refuge, particularly in situations where interspecific competition is strong or leads to intraguild predation, i.e., one competitor predates another (Frago 2016). Since negative interactions between control agents significantly influence pest suppression (Denoth, Frid, \& Miers 2002), in food webs where parasitoids and predators are natural enemies of a pest a desirable outcome for biological control would be parasitised prey avoidance by predators.

In agroecosystems, parasitoids and predators may exert top-down regulation, as the system is less heterogeneous over space and time (Schmidt et al. 2003), and interactions amongst them affect herbivore populations in different ways. Because intraguild predation seems to be ubiquitous in nature (Arim \& Marquet 2004), parasitoid-predator interactions go beyond exploitative competition and predators may avoid or give preference to parasitised prey, for various reasons.

In a scenario with indirect effects of intraguild predation, where predators do not avoid parasitised prey, these predators may, under suitable conditions, coexist with parasitoids (intraguild prey). First, when competition is weak, as may happen due to generalist behaviour of predators and frequency-dependent predation. Second, when intraguild predation occurs the conditions for species coexistence may change, depending on the lower relative efficiency in resource exploitation by intraguild predators than by intraguild prey (Holt \& Polis 1997; Arim \& Marquet 2004). Essentially, when suppressing pests with multiple natural enemies, there are two key points to be observed, (1) whether a natural enemy displaces the other, as in the case of specialist predators or lack of refuge given overlapping niches, and (2) the interplay between predation and parasitism, i.e. avoidance of parasitised prey or intraguild predation. A greater diversity of natural enemies can either enhance or disrupt pest suppression, depending on the niches of the species involved in the food web and whether antagonistic interactions occur, such as intraguild predation (Frago 2016).

Here we study how parasitism affects predator choice using pest, predator and parasitoid species that naturally occur in agroecosystems. We conduct a simple experiment in which two predator species are offered a choice between parasitised and non-parasitised prey and use statistical models to predict the probability of a predator consuming the other prey given its first choice. Our hypothesis is that predators distinguish parasitised from non-parasitised prey and have a preference towards feeding on a particular type of prey, which can be species- and/or sex-specific. We observe how parasitismmediated predation occurs and discuss, based on ecological theory, the effects of this type of predation and possible consequences on population dynamics. Finally, we highlight and discuss implications for biological control.

\section{Materials and methods}

\section{Biology and natural history}

The fall armyworm Spodoptera frugiperda (Lepidoptera: Noctuidae) is one of the most important maize pests worldwide, given its capability of substantially reducing productivity in these agroecosystems (Desneux, Ramírez- 
Romero, Bokonon-Ganta, \& Bernal 2010). There are several predators that feed on $S$. frugiperda larvae and eggs, amongst which two generalist species, the Neotropical stinkbug Podisus nigrispinus (Hemiptera: Pentatomidae) and the ring-legged earwig Euborellia annulipes (Dermaptera: Anisolabididae), naturally occur in maize fields and are considered promising natural enemies (Lemos, Ramalho, \& Zanuncio 2003; De Bortoli, Otuka, Vacari, Martins, \& Volpe 2011). These predators have different feeding habits. Even though both touch prey with their antennae prior to predation, $P$. nigrispinus inserts its mouth parts into the prey to suck its hemolymph, while E. annulipes uses its forceps to hold prey and then feeds using its chewing mouth parts.

The parasitoid wasp Campoletis flavicincta (Hymenoptera: Ichneumonidae) is also naturally found in maize and shows great potential in controlling $S$. frugiperda (Matos Neto, Cruz, Zanuncio, Silva, \& Picanço 2004). This species lays one to four eggs on S. frugiperda larvae and when these eggs eventually hatch they develop inside the host, killing it by the time adult parasitoids emerge from their pupae (Patel \& Habib 1987). When a larva is parasitised its physiology changes, most notably, in a biological control context, its growth decelerates reducing resource consumption, eventually leading to death (Godfray 1994; Beckage \& Gelman 2004). Similarly, when the predators attack, even though they may not entirely consume larvae, the damage they inflict when inserting the mouth part (P. nigrispinus) or holding prey with the forceps ( $E$. annulipes) may reduce resource consumption and even kill larvae, although not instantly.

\section{Parasitism and choice tests}

In this work our goals were to determine whether the predators (1) were able to distinguish parasitised larvae from non-parasitised larvae and (2) had preference for feeding on one of these larvae in two-choice systems. To achieve this, $S$. frugiperda larvae were obtained from Laboratório de Biologia de Insetos of ESALQ-USP, Piracicaba, São Paulo, Brazil. P. nigrispinus eggs were obtained from EMBRAPA (Campina Grande, Paraíba, Brazil) and maintained in Petri dishes with moist cotton until they hatched. Immature specimens were maintained in these same Petri dishes and received only distilled water until they reached the third instar, from which specimens were transferred to plastic containers $(350 \mathrm{ml}-$ around 20 individuals per container) with glass tubes filled with water and sealed with cotton attached to the lid. Specimens were then offered $S$. frugiperda larvae and when adults emerged, different couples were selected and kept in separate containers of the same type. E. annulipes eggs were obtained from Universidade Federal da Paraíba, Areia, Paraíba, Brazil and maintained in Petri dishes on moist paper until they hatched. Nymphs were maintained in the same Petri dishes until adults emerged, which were separated in plastic containers ( $350 \mathrm{ml}$ - three couples in each container). Specimens received an artificial diet consisting of 50\% corn powder, $25 \%$ powdered milk and $25 \%$ silkmoth pupae powder, replaced every two days. C. flavicincta adults were obtained from Laboratório de Resistência de Artrópodes a Táticas de Controle of ESALQ-USP, Piracicaba, São Paulo, Brazil. All insects were maintained in climatised chambers at $25^{\circ} \mathrm{C}, 70 \%$ relative humidity and $12 \mathrm{~h}$ photophase, with the exception of E. annulipes, for which the temperature was $26^{\circ} \mathrm{C}$ and the photophase was $10 \mathrm{~h}$.

An experiment was conducted using Petri dishes on which one adult specimen of $P$. nigrispinus or E. annulipes was placed together with two $S$. frugiperda third instar larvae, one of which had been previously parasitised by $C$. flavicincta (Fig. 1). Parasitised and non-parasitised larvae were placed individually in small plastic containers $(3 \times 2 \times 2 \mathrm{~cm}) 24 \mathrm{~h}$ prior to experiment set up and predators were fasted for the same period of time. The experiment was carried out using a randomised complete block design with 33 temporal blocks and four treatments in a $2 \times 2$ (sex and species) factorial structure: P. nigrispinus males and females and $E$. annulipes males and females (Fig. 1).

Each experimental unit was observed for one hour and the following were recorded: (1) how long the predator took to attack; (2) which prey was attacked first; (3) which prey was effectively consumed (since the predator may opt to interrupt consumption to consume the other prey); and (4) whether both prey were consumed within one hour. The possible outcomes are summarised in Fig. 2.

\section{Statistical analyses}

For the time until attack data, Cox proportional hazards models (Aitkin, Francis, Hinde, \& Darnell 2009) were fit with a linear predictor given by

$\eta_{i j k}=\beta_{j}+\alpha_{i}+\gamma_{k}+(\alpha \gamma)_{i k}, i=1,2, j=1, \ldots, 33, k=1,2$,

where $\beta_{j}$ is the effect of the $j$-th block, $\alpha_{i}$ is the effect of the $i$-th species, $\gamma_{k}$ is the effect of the $k$-th sex and $(\alpha \gamma)_{i k}$ is the interaction effect between the $i$-th species and the $k$-th sex. Likelihood ratio tests (LRT), that compare nested models using the maximised likelihood functions, were used to evaluate submodels. In the following, the LRT statistic is represented by $\lambda$ and, under the null hypothesis of the simpler model being true, it has an asymptotic $\chi^{2}$ distribution with degrees of freedom equal to the difference between the number of parameters of the compared models (Aitkin et al. 2009).

Binomial generalised linear models (McCullagh \& Nelder 1989) were used to analyse binary response variables relating to attack and consumption, in two stages. In stage one, logistic regressions with a linear predictor given by (M1) were fit to (a) an attack occurrence indicator variable (equal to 1 if there was an attack during one hour of experiment and equal to 0 , if there was not) and (b) an effective consumption 
(A)

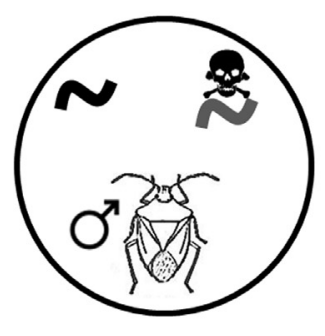

(C)

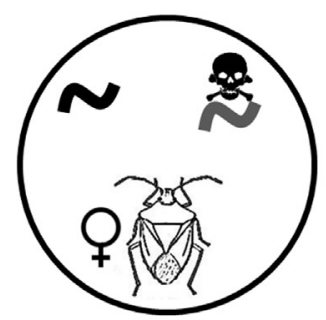

(B)

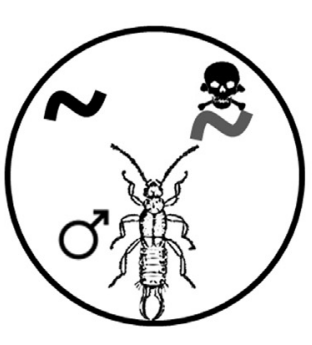

(D)

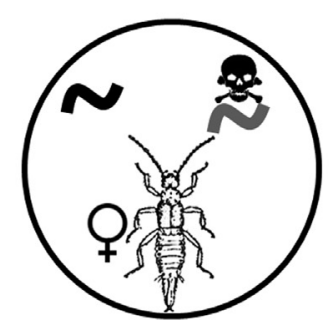

205

○㐿 Male $P$. nigrispinus

○ Female P. nigrispinus

O'旗 Male E. annulipes

है

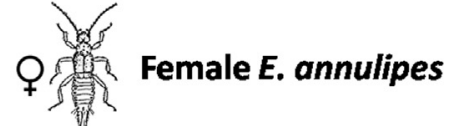

Non-parasitised larva

Parasitised larva

Fig. 1. Experimental treatments - two $S$. frugiperda larvae, one of which was previously parasitised by C. flavicincta with (A) a P. nigrispinus male, (B) an E. annulipes male, (C) a P. nigrispinus female and (D) an E. annulipes female.

(A)

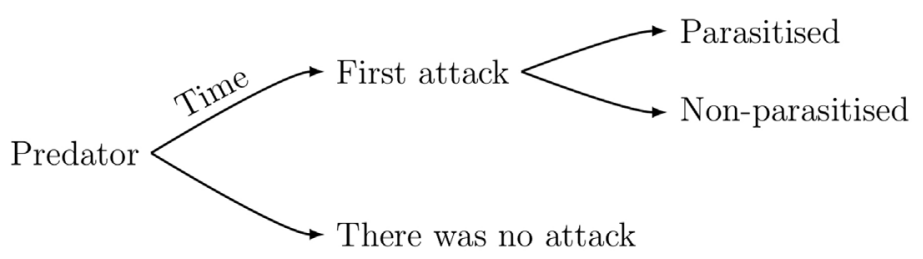

(B)

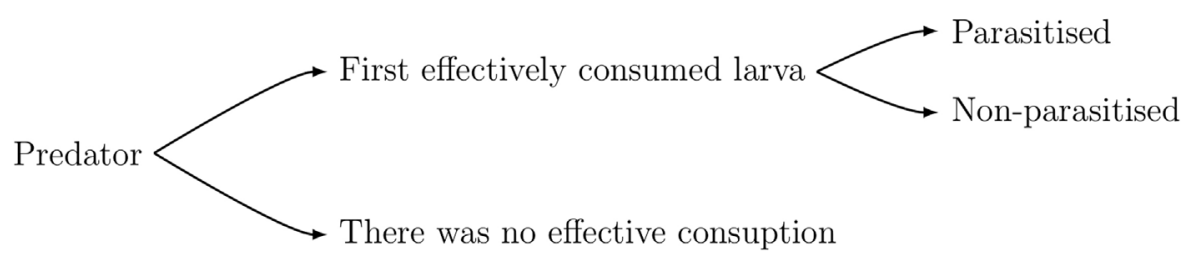

Fig. 2. Response variables observed in the experiment in two stages, for (A) first attack and (B) effective consumption.

occurrence indicator variable (equal to 1 if a larva was effectively consumed in one hour and equal to 0 , otherwise). In stage two, logistic regressions with the same linear predictor were fit to (a) the variable "given that there was an attack, which larva was attacked first" (equal to 1 if it was the parasitised larva and equal to 0 otherwise) and (b) the variable "given that there was an effectively consumed larva, which one was consumed first" (equal to 1 if it was the parasitised larva and equal to 0 otherwise), see Fig. 2. In addition, to explore the dependence of the attack behaviour on time, for the stage two analyses, the natural logarithm of the time until attack was included in the linear predictor (M1) giving a maximal model

$\eta_{i j k}=\beta_{j}+\alpha_{i}+\gamma_{k}+(\alpha \gamma)_{i k}+\delta_{i k} \log \left(t_{i j k}\right)$,

with species and sex specific time dependence. Again, all possible submodels were compared using likelihood-ratio tests.

Noting that predators may attack one larva and opt to effectively consume the other, a $2 \times 2 \times 2 \times 2$ contingency 
Table 1. $2 \times 2$ contingency table for first attack and effective consumption and possible outcomes of prey switching, considering probabilities $\pi_{1}$ and $\pi_{2}$ of consuming the other prey, given the predator first attacked the non-parasitised larva and the parasitised larva, respectively.

\begin{tabular}{lll}
\hline First attacked prey & Effectively consumed prey & \\
\cline { 2 - 3 } & Non-parasitised larva & Parasitised larva \\
\hline $\begin{array}{ll}\text { Non-parasitised larva } \\
\text { Parasitised larva }\end{array}$ & Predator does not switch prey with probability $1-\pi_{1}$ & Predator switches prey with probability $\pi_{1}$ \\
\hline
\end{tabular}

table was constructed for the binary variables species, sex, first attacked larva, and effectively consumed larva. For each species by sex combination, we have the $2 \times 2$ table of possible responses as in Table 1 . Generically, suppose that $\pi_{1}$ is the probability of consuming the other prey given the predator has attacked the non-parasitised larva first and $\pi_{2}$ is the probability of consuming the other prey given it has attacked the parasitised larva first. Two situations may occur: (1) if the predator is not able to distinguish a parasitised larva from a non-parasitised one, or is able to do it but does not have a preference, we would expect that $\pi_{1}=\pi_{2}=\pi$, say; (2) if the predator can distinguish parasitised larvae and has a preference for a prey type, then we would expect that $\pi_{1} \neq \pi_{2}$. The interest here is to assess whether the different species and sex combinations would have different probabilities of consuming the other prey given the type of larva they attacked first. Initially, a logistic regression model (McCullagh \& Nelder 1989) was fitted with a linear predictor given by

$\eta_{i j k}=\alpha_{i}+\gamma_{j}+\tau_{k}+(\alpha \gamma)_{\mathrm{ij}}+(\alpha \tau)_{\mathrm{ik}}+(\gamma \tau)_{\mathrm{jk}}+(\alpha \gamma \tau)_{\mathrm{ijk}}$,

where $\alpha_{i}, i=1,2$, is the species effect, $\gamma_{j}, j=1,2$, is the sex effect, and $\tau_{k}, k=1,2$, is the effect of consuming a different type of prey than the one that was attacked first, comprising eight parameters, i.e. giving a different probability of consuming the other prey given the predator's first attack for each species and sex combinations. All submodels were also fitted and compared using likelihood-ratio tests.

All analyses were carried out using statistical software R (R Core Team 2015). The Cox proportional hazards models were fit using function "coxph" from the package "survival" (Therneau 2015) and binomial generalised linear models were fit using function "glm" from the package "stats" (R Core Team 2015).

\section{Results}

\section{Time until attack}

Our results showed evidence that female earwigs are more aggressive and are prone to attack sooner than male earwigs, which, in turn, are more aggressive than male and female stinkbugs. Fitting the Cox proportional hazards model with linear predictor (M1), there was no evidence of a block effect $(\lambda=37.07$, on 32 d.f., $p=0.25)$ while the interaction between species and sex was significant $(\lambda=4.37$, on 1 d.f., $p=0.04)$. Refitting the Cox model without a block effect in the linear predictor (M1) the interaction was still significant $(\lambda=7.17$, on 1 d.f., $p<0.01$ ). The hypothesis that hazards were proportional (Grambsch \& Therneau 1994) was not rejected (global test statistic $=2.33$, on 3 d.f., $p=0.51$ ) and hence the Cox proportional hazards model can be considered as appropriate. It was found that the hazard does not differ for males and females of $P$. nigrispinus ( $\lambda=1.48$, on 1 d.f., $p=0.22$ ), while the hazard for females of $E$. annulipes is higher than for males $(\lambda=6.78$, on 1 d.f., $p<0.01)$.

\section{First attack and effective consumption}

Fitting a logistic regression to the attack occurrence indicator variable using the linear predictor (M1) (stage one), the interaction effect was not significant $(\lambda<0.01$, on 1 d.f., $p=1.00)$, but it was found that there was a significant species effect $(\lambda=5.18$, on 1 d.f., $p=0.02)$. Only three individuals did not attack in one hour of observation and they were all stinkbugs. For the effective consumption indicator variable, the interaction effect was again not significant $(\lambda=2.82$, on 1 d.f., $p=0.09)$, however there was a marginally significant sex effect ( $\lambda=3.77$, on 1 d.f., $p=0.052)$. Stinkbugs and female earwigs did not effectively consume any larva in only three out of 33 replicates, while male earwigs did not effectively consume a larva in nine replicates.

Considering the stage two analysis of the first attack variable, the logistic regression verified that there was a marginally significant interaction effect $(\lambda=3.79$, on 1 d.f., $p=0.052$ ). Summarising these data in a $2 \times 2 \times 2$ contingency table for first attacked prey, species and sex (Table 2A) the odds-ratios showed that male earwigs are more prone to choosing parasitised larvae on their first attack than females, while for stinkbugs, females are more prone to do so than males.

For the stage two analysis of the effective consumption variable, the logistic regression fit gave a non-significant interaction effect ( $\lambda=0.13$, on 1 d.f., $p=0.72)$, but the main effects indicated a clearly significant effect of $\operatorname{sex}(\lambda=8.31$, on 1 d.f., $p<0.01$ ). Summarising these data in a collapsed $2 \times 2$ contingency table for effectively consumed prey and sex (Table 2B), we observe that males choose to consume non-parasitised larvae with a greater probability than females.

Now extending the model for stage two to include the logarithm of time until attack (linear predictor (M2)): (1) for 
(A)

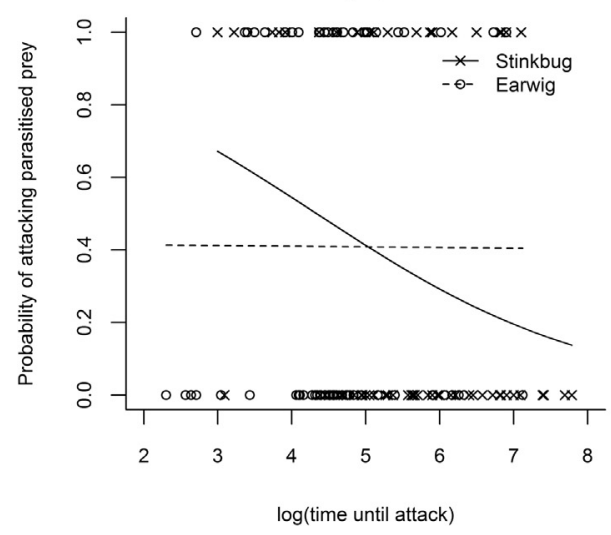

(B)

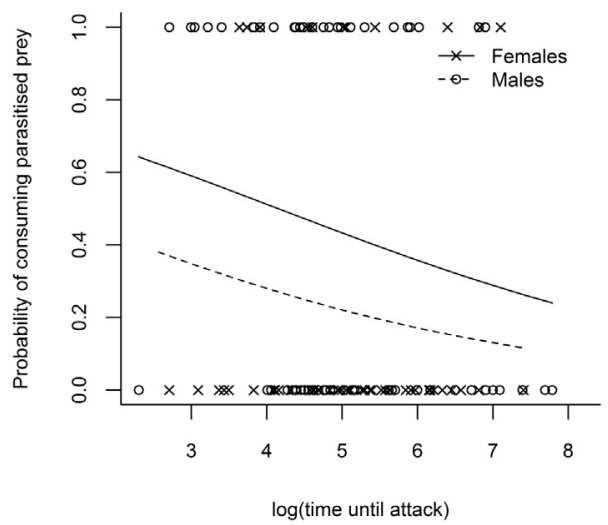

Fig. 3. (A) Stinkbug (solid line) and earwig (dashed line) predicted probabilities of attacking parasitised prey over time obtained from the selected model; (B) female (solid line) and male (dashed line) predicted probabilities of effectively consuming parasitised prey over time obtained from the selected model.

Table 2. Contingency tables and odds-ratio for (A) first attacked prey, species and sex, (B) effectively consumed prey and sex, and (C) consumption of both prey (yes or no), species and sex. NP = nonparasitised larva, $\mathrm{P}=$ parasitised larva.

(A) First attack

\begin{tabular}{llrrl}
\hline & & NP & P & Odds-ratio \\
\hline P. nigrispinus & Male & 24 & 8 & 2.47 \\
& Female & 17 & 14 & \\
E. annulipes & Male & 18 & 15 & 0.69 \\
& Female & 21 & 12 &
\end{tabular}

(B) Effective consumption

\begin{tabular}{lllll}
\hline & & NP & P & Odds-ratio \\
\hline Both species & Male & 42 & 12 & 2.68 \\
& Female & 34 & 26 &
\end{tabular}

(C) Consumption of both larvae

\begin{tabular}{lllrl}
\hline & & No & Yes & Odds-ratio \\
\hline P. nigrispinus & Male & 23 & 10 & 1.31 \\
& Female & 21 & 12 & \\
E. annulipes & Male & 26 & 7 & 8.54 \\
& Female & 10 & 23 & \\
\hline
\end{tabular}

first attack, the final selected model included the effects of block, species and a species specific time effect $(\lambda=4.36$, on 1 d.f., $p=0.04)$, and hence different linear predictors for each species; (2) for effective consumption, the final selected model included the effects of block, $\operatorname{sex}(\lambda=7.68$, on 1 d.f., $p=0.01)$ and only a common time effect $(\lambda=12.32$, on 1 d.f., $p<0.01$ ), corresponding to parallel linear predictors over time for each sex. Therefore, the time until first attack influences the estimated probability of predators attacking the parasitised larva differently for each species $\left(\hat{\pi}_{\text {stinkbug }}=\exp \{2.31-0.53 \times \log (\right.$ time $)\} /(1+\exp \{2.31$
$-0.53 \times \log ($ time $)\}) \quad$ and $\quad \hat{\pi}_{\text {earwig }}=\exp \{-0.33-0.01$ $\times \log ($ time $)\} /(1+\exp \{-0.33-0.01 \times \log ($ time $)\})), \quad$ see Fig. 3A. For effective consumption, females are more prone to consume the parasitised larva than males, but this estimated probability decreases with time until attack at the same rate for both males and females $\left(\hat{\pi}_{\text {male }}=\exp \{0.32-0.32\right.$ $\times \log ($ time $)\} /(1+\exp \{0.32-0.32 \times \log ($ time $)\}) \quad$ and $\hat{\pi}_{\text {female }}=\exp \{1.32-0.32 \times \log ($ time $)\} /(1+\exp \{1.32$ $-0.32 \times \log ($ time $)\}))$, see Fig. 3B.

Considering the binary variable of whether the predator consumed both prey in one hour of observation, given that there was an effective consumption, from the logistic regression fit there is evidence of a significant interaction effect $(\lambda=10.32$, on 1 d.f., $p<0.01)$. Summarising these data in a $2 \times 2 \times 2$ contingency table for consumption of both prey, sex and species (Table 2C) the odds-ratios showed that female earwigs appear to need more resource than males.

\section{Estimating the probability of attacking a larva and consuming the other}

Fitting (P1) and all possible submodels, from likelihoodratio tests for nested models, there is evidence that the best model includes an interaction between sex and alternative prey consumption and an additive species effect (see Appendix A - Supplemetary data). Therefore, males have a stronger preference for non-parasitised prey while females seem to have no preference (see Fig. 4).

\section{Discussion}

In a maize field, P. nigrispinus and E. annulipes can compete for $S$. frugiperda. Moreover, the parasitoid C. flavicincta is exposed to indirect predation when predators feed on parasitised prey. Coexistence is possible for predators and parasitoids due to frequency-dependent predation, in which 


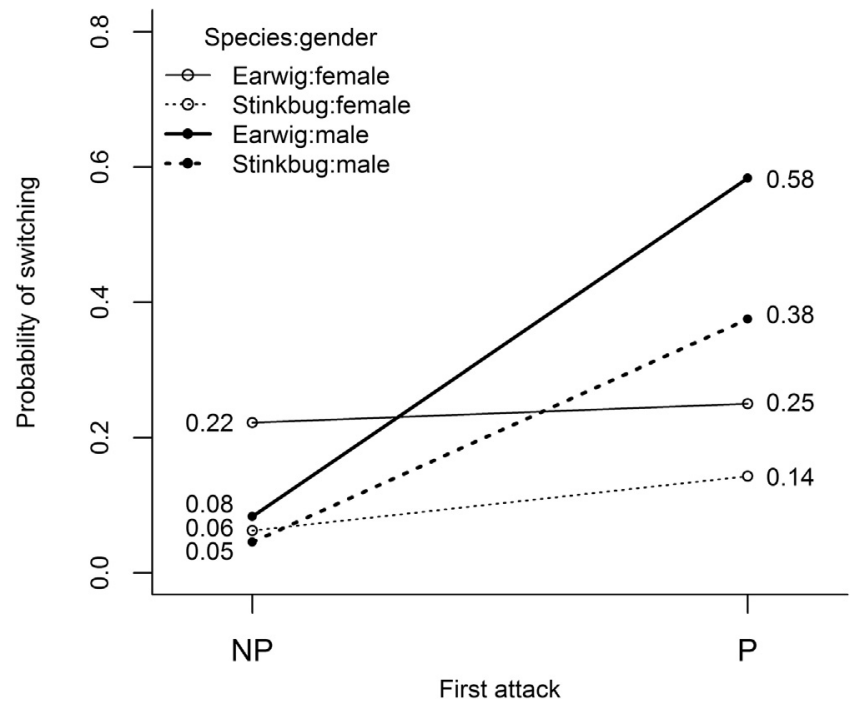

Fig. 4. Estimated probabilities of prey switching given the first attack was on a non-parasitised (NP) or parasitised (P) larva for each species and sex combination.

generalist predators are most likely to consume more abundant prey, in this case non-parasitised larvae, in response to spatio-temporal variation in resource availability (Chesson 2000). Also, in maize fields, top-down control of pests may be stronger if there is more species diversity (which may result from a polyculture, for example), due to the greater number of links in the food webs (Zhang \& Adams 2011).

Parasitoid population dynamics are heavily influenced by competing parasitoids or intraguild predation. The latter may lower the probability of a parasitoid completing its development and hence persisting in the system (Duffy, Hall, Tessier, \& Huebner 2005). Even though in many studies predators opt to avoid parasitised prey, it is possible that some species prefer to feed on this type of prey (Packer, Holt, Hudson, Lafferty, \& Dobson 2003). This may be due to several factors, such as higher susceptibility to predation, behavioural changes induced by parasitism, or simply due to parasitoids and predators choosing the same host/prey because they prefer the same phenotypic traits (Knudsen, Gabler, Kursi, \& Amundsen 2001). Even though at first the combined effect of a generalist predator and a parasitoid on pest suppression may be an immediate decrease in pest density, this can be overturned over the following generations due to reduced parasitism rates, caused by intraguild predation (Snyder \& Ives 2001).

Here we conducted a laboratory experiment to investigate how parasitism affected predator choice in a biological control context. It is important to note that this was a Petri-dish study, representing a simple way of observing the species' behaviour under controlled circumstances and was, hence, limited to such settings. We used statistical models to study the system and to estimate the probabilities of consuming parasitised prey or consuming a different prey, given the predator's first choice. Results suggested that predators are able to distinguish parasitised prey, however males tend to avoid them. This lack of selectiveness in females is likely to be related to their reproductive physiology and in the case of $E$. annulipes, their aggressive behaviour as well (Klostermeyer 1942). Also, as the metabolic requirements of females are usually higher, the $24 \mathrm{~h}$ fasting may have influenced this behaviour more than it did for males (Kolluru, Chappel, \& Zuk 2004; Hodin 2009). Moreover, Petri-dish studies can be biased towards artificially high intraguild predation rates (Ingels \& De Clercq 2011).

When a predator takes longer to attack a prey, one possible explanation could be natural individual variability, with the 24-h fasting affecting each insect differently (Fig. 3). Traditional population dynamics models usually neglect differences between sexes and the high degree of variation in attack rates, which highly influence population trajectories over time and ecological relationships (Schreiber, Bürger, $\&$ Bolnick 2011). Statistical models such as the ones used in this work are particularly useful in describing individual variation so that it can be used to alter pest-enemy or predator-parasitoid-host models. The probability of consuming a specific type of prey can be included in these models to study these indirect effects of intraguild predation under different settings, theoretically.

Our results also suggest that the longer a predator takes to attack, the more likely it is to consume nonparasitised prey (Fig. 3B). In other studies, involving different pests and natural enemies, this avoidance behaviour was also found for Serangium parcesetosum, which prefers to feed on non-parasitised Bemisia tabaci larvae (Al-Zyoud \& Sengonca 2004), for females of Rodolia cardinalis and Delphastus pusillus, which avoid parasitised Icerya purchase larvae (Quezada \& Debach 1973; Hoelmer, Osborne, \& Yokomi 1994) and for Geocoris punctipes, which avoids whitefly nymphs parasitised by Eretmocerus eremicus (Velasco-Hernández, Ramirez-Romero, Cicero, Michel-Rios, \& Desneux 2013). While it may not be universally true, this avoidance may be due to inferior nutritional quality of parasitised prey, for example Bilu and Coll (2009) showed that parasitised Myzus persicae nymphs were nutritionally inferior to their predator, Coccinella undecimpunctata, whose development time increased and weight gain was slower when feeding on parasitised prey.

These results highlight the importance of studies on natural enemy interactions, as well as coexistence mechanisms in agroecosystems. Biological control strategies involving multiple natural enemies must be carefully studied, since pest suppression success is dependent upon ecological relations amongst these species as well as their intensity (Amarasekare 2000). When parasitism mediates predator choice, in a sense that intraguild predation is avoided, natural enemies may coexist in the agroecosystem and biological control is more likely to be successful. Examples of successful pest suppression using different predators and a parasitoid in combination can be found in Snyder, Snyder, Finke, and Straub (2006) and in Gontijo, Beers, and Snyder (2015). On the other hand, if 
generalist predators prefer to feed on parasitised prey, pest suppression due to parasitism is likely to be disrupted (e.g. Traugott, Bell, Raso, Sint, \& Symondson 2012).

Future work includes laboratory and field experiments to assess coexistence amongst these natural enemies as well as the development of mathematical models to predict time of extinction and population dynamics of the system. Moreover, studies assessing parasitism chemical signaling pathways to determine how predators distinguish parasitised prey would also be of interest. Finally, long-term experiments are needed for a more comprehensive understanding of these interactions (Frago 2016).

\section{Acknowledgements}

RAM received financial support by FAPESP (proc. no. 2011/15253-6 and 2014/12903-8). Exchange visits between CGBD and JH were supported by CNPq, FAPESP and SFI. WACG was supported by CNPq. FSF was supported by CAPES.

\section{Appendix A. Supplementary data}

Supplementary data associated with this article can be found, in the online version, at http://dx.doi.org/10.1016/j.baae.2016.11.002.

\section{References}

Aitkin, M., Francis, B., Hinde, J., \& Darnell, R. (2009). Statistical modelling in R. Oxford: Oxford University Press., $576 \mathrm{p}$

Al-Zyoud, F., \& Sengonca, C. (2004). Prey consumption preferences of Serangium parcesetosum Sicard (Col., Coccinelidae) for different prey stages, species and parasitized prey. Journal of Pest Science, 77, 197-204.

Amarasekare, P. (2000). Coexistence of competing parasitoids on a patchily distributed host: Local vs. spatial mechanisms. Ecology, 81, 1286-1296.

Arim, M., \& Marquet, P. A. (2004). Intraguild predation: A widespread interaction related to species biology. Ecology Letters, 7, 557-564.

Beckage, N. E., \& Gelman, D. B. (2004). Wasp parasitoid disruption of host development: Implications for new biologically based strategies for insect control. Annual Review of Entomology, 49, 299-330.

Bilu, E., \& Coll, M. (2009). Parasitized aphids are inferior prey for a coccinellid predator: Implications for intraguild predation. Environmental Entomology, 38, 153-158.

Cardinale, B. J., Harvey, C. T., Gross, K., \& Ives, A. R. (2003). Biodiversity and biocontrol: Emergent impacts of a multi-enemy assemblage on pest suppression and crop yield in an agroecosystem. Ecology Letters, 6, 857-865.

Chesson, P. (2000). Mechanisms of maintenance of species diversity. Annual Review of Ecology Evolution and Systematics, 31, 343-366.
De Bortoli, S. A., Otuka, A. K., Vacari, A. M., Martins, M. I. E. G., \& Volpe, H. X. L. (2011). Comparative biology and production costs of Podisus nigrispinus (Hemiptera: Pentatomidae) when fed different types of prey. Biological Control, 58, 127-132.

Denoth, M., Frid, L., \& Myers, J. H. (2002). Multiple agents in biological control: Improving the odds? Biological Control, 24, 20-30.

Desneux, N., Ramírez-Romero, R., Bokonon-Ganta, A. H., \& Bernal, J. S. (2010). Attraction of the parasitoid Cotesia marginiventris to host (Spodoptera frugiperda) frass is affected by transgenic maize. Ecotoxicology, 19, 1183-1192.

Duffy, M. A., Hall, S. R., Tessier, A. J., \& Huebner, M. (2005). Selective predators and their parasitized prey: Are epidemics in zooplankton under top-down control? Limnology and Oceanography, 50, 412-420.

Ferguson, K. I., \& Stiling, P. (1996). Non-additive effects of multiple natural enemies in aphid populations. Oecologia, 108, 375-379.

Frago, E. (2016). Interactions between parasitoids and higher order natural enemies: Intraguild predation and hyperparasitoids. Current Opinion in Insect Science, 14, 81-86.

Godfray, H. C. J. (1994). Parasitoids: Behavioral and evolutionary ecology. Princeton: Princeton University Press., 488 p.

Gontijo, L. M., Beers, E. H., \& Snyder, W. E. (2015). Complementary suppression of aphids by predators and parasitoids. Biological Control, 90, 83-91.

Grambsch, P., \& Therneau, T. (1994). Proportional hazards tests and diagnostics based on weighted residuals. Biometrika, 81, $515-526$.

Hodin, J. (2009). She shapes events as they come: Plasticity in female insect reproduction. In D. W. Whitman, \& T. N. Ananthakrishnan (Eds.), Phenotypic plasticity of insects: Mechanisms and consequences. Enfield: Science Publishers, 500 p.

Hoelmer, K. A., Osborne, L. S., \& Yokomi, R. K. (1994). Interaction of the whitefly predator Delphastus pusillus (Col., Coccinelidae) with parasitized sweet potato whitefly (Hom., Aleyrodidae). Environmental Entomology, 23, 136-139.

Holt, R. D., \& Polis, G. A. (1997). A theoretical framework for intraguild predation. The American Naturalist, 149, 745-764.

Ingels, B., \& De Clercq, P. (2011). Effect of size, extraguild prey and habitat complexity on intraguild interactions: A case study with the invasive ladybird Harmonia axyridis and the hoverfly Episyrphus balteatus. BioControl, 56, 871-882.

Klostermeyer, E. (1942). The life history and habits of the ringlegged earwig, Euborellia annulipes (Lucas) (Order Dermaptera). Journal of the Kansas Entomological Society, 15, 13-18.

Knudsen, R., Gabler, H. M., Kursi, A. M., \& Amundsen, P. A. (2001). Selective predation on parasitized prey-A comparison between two helminth species with different life-history strategies. Journal of Parasitology, 87, 941-945.

Kolluru, G. R., Chappel, M. A., \& Zuk, M. (2004). Sex differences in metabolic rates in field crickets and their dipteran parasitoids. Journal of Comparative Physiology B: Biochemical Systemic and Environmental Physiology, 174, 641-648.

Lemos, W. P., Ramalho, F. S., \& Zanuncio, J. C. (2003). Agedependent fecundity and life-fertility tables for Euborellia annulipes (Lucas) (Dermaptera: Anisolabididae) a cotton boll weevil predator in laboratory studies with an artificial diet. Environmental Entomology, 32, 592-601.

Matos Neto, F. C., Cruz, I., Zanuncio, J. C., Silva, C. H. O., \& Picanço, M. C. (2004). Parasitism by Campoletis flavicincta 
on Spodoptera frugiperda in corn. Pesquisa Agropecuária Brasileira, 39, 1077-1081.

McCullagh, P., \& Nelder, J. A. (1989). Generalized linear models. London: Chapman and Hall., 511 p.

Packer, C., Holt, R. D., Hudson, P. J., Lafferty, K. D., \& Dobson, A. P. (2003). Keeping the herds healthy and alert: Implications of predator control for infectious disease. Ecology Letters, 6, 797-802.

Patel, P. N., \& Habib, M. E. M. (1987). Biological studies on Campoletis flavicincta (Ashmead, 1890) (Hym., Ichneumonidae), an endoparasitic of the fall armyworm, Spodoptera frugiperda (Abbot \& Smith, 1797) (Lepid., Noctuidae). Journal of Applied Entomology, 104, 28-35.

Quezada, J. R., \& Debach, P. (1973). Bioecological and population studies of the cottony-cushion scale, Iceria purchasi Mask. and its natural enemies, Rodolia cardinalis Mul. and Cryptochaetum iceryae Will. in southern California. Hilgardia, 41, 631-688.

R Core Team. (2015). R: A language and environment for statistical computing. Vienna, Austria: R Foundation for Statistical Computing. http://www.R-project.org/

Schmidt, M. H., Lauer, A., Purtauf, T., Thies, C., Schaefer, M., \& Tscharnkte, T. (2003). Relative importance of predators and parasitoids for cereal aphid control. Proceedings of the Royal Society B, 270, 1905-1909.
Schreiber, S. J., Bürger, R., \& Bolnick, D. I. (2011). The community effects of phenotypic and genetic variation within a predator population. Ecology, 92, 1582-1593.

Snyder, W. E., \& Ives, A. R. (2001). Generalist predators disrupt biological control by a specialist parasitoid. Ecology, 82, 705-716.

Snyder, W. E., Snyder, G. B., Finke, D. L., \& Straub, C. S. (2006). Predator biodiversity strengthens herbivore suppression. Ecology Letters, 9, 789-796.

Therneau, T. (2015). A package for survival analysis in $S$, version 2.38. http://CRAN.R-project.org/package=survival

Traugott, M., Bell, J. R., Raso, L., Sint, D., \& Symondson, W. O. C. (2012). Generalist predators disrupt parasitoid aphid control by direct and coincidental intraguild predation. Bulletin of Entomological Research, 102, 239-247.

Velasco-Hernández, M. C., Ramirez-Romero, R., Cicero, L., Michel-Rios, C., \& Desneux, N. (2013). Intraguild predation on the whitefly parasitoid Eretmocerus eremicus by the generalist predator Geocoris punctipes: A behavioral approach. PLoS One, e80679.

Zhang, Y., \& Adams, J. (2011). Top-down control of herbivores varies with ecosystem types. Journal of Ecology, 99, 370-372.

Available online at www.sciencedirect.com 